Supporting Information for

\title{
Coal Is Dirty, but Where It Is Burned Especially Matters
}

Xiao Yun, Wenjun Meng, Haoran Xu, Wenxiao Zhang, Xinyuan Yu, Huizhong Shen, Yilin Chen, Guofeng Shen, Jianmin Ma, Bengang Li, Hefa Cheng, Jianying Hu, and Shu Tao*

College of Urban and Environmental Sciences, Laboratory for Earth Surface Processes, SinoFrench Institute for Earth System Science, Peking University, Beijing 100871, China.

*Corresponding author. Email: taos@ pku.edu.cn

There are 8 figures and 1 table. 


\section{Calculation of the Infiltration Factor}

The infiltration factor represents the indoor/outdoor $\mathrm{PM}_{2.5}$ concentration ratios in the absence of indoor solid fuel combustion sources. For households without indoor solid fuel combustion source, indoor $\mathrm{PM}_{2.5}$ concentration was calculated by multiplying the WRF/Chem-modeled ambient $\mathrm{PM}_{2.5}$ concentration with the infiltration factor. The infiltration factor was calculated based on the following equation from Xiang et al.: ${ }^{1}$

$$
F_{\text {inf }}=\frac{A E R_{\text {open }} \times p_{\text {open }}}{A E R_{\text {open }}+k} \times \frac{t_{\text {open }}}{t_{\text {open }}+t_{\text {closed }}}+\frac{A E R_{\text {closed }} \times p_{\text {closed }}}{A E R_{\text {closed }}+k} \times \frac{t_{\text {closed }}}{t_{\text {open }}+t_{\text {closed }}}
$$

where $F_{\text {inf }}$ is the indoor/outdoor $\mathrm{PM}_{2.5}$ infiltration factor; $A E R_{\text {open }}$ and $A E R_{\text {closed }}$ are building air exchange rates when the doors and windows are open and closed, respectively; $p_{\text {open }}$ and $p_{\text {closed }}$ are building $\mathrm{PM}_{2.5}$ penetration factors when the doors and windows are open and closed, respectively; $t_{\text {open }}$ and $t_{\text {closed }}$ are the time the doors and windows are open and closed, respectively; $k$ is the first order deposition rate of $\mathrm{PM}_{2.5}$ to indoor surface.

Monte Carlo simulations were performed 1,000 times to characterize uncertainties in calculation of infiltration factors. $A E R_{\text {open }}$ was normally distributed with means of $4.38 \mathrm{~h}^{-1}$ and standard deviations of 2.45 $\mathrm{h}^{-1}{ }^{2} A E R_{\text {closed }}$ for northern China was log-normally distributed with means of $0.14 \mathrm{~h}^{-1}$ and standard deviations of $0.07 \mathrm{~h}^{-1}$ in nonheating seasons, and with means of $0.31 \mathrm{~h}^{-1}$ and standard deviations of $0.27 \mathrm{~h}^{-}$ ${ }^{1}$ in heating seasons; $A E R_{\text {closed }}$ for southern China is $0.7 \mathrm{~h}^{-1}$ in both heating and nonheating seasons. ${ }^{3}$ Values of 1.0 and 0.8 for $p_{\text {open }}$ and $p_{\text {closed }}$, and a value of $0.2 \mathrm{~h}^{-1}$ for $k$ were adopted, respectively. ${ }^{4}$ Provincial $t_{\text {open }}$ and $t_{\text {closed }}$ for rural and urban households in heating and nonheating seasons were obtained from an exposure factor handbook. ${ }^{5}$ The infiltration factors were calculated by provinces, areas (urban and rural), and seasons (heating and nonheating seasons), respectively. Generally, infiltration factors are higher in southern China than in northern China, and higher in nonheating seasons than in heating seasons. 

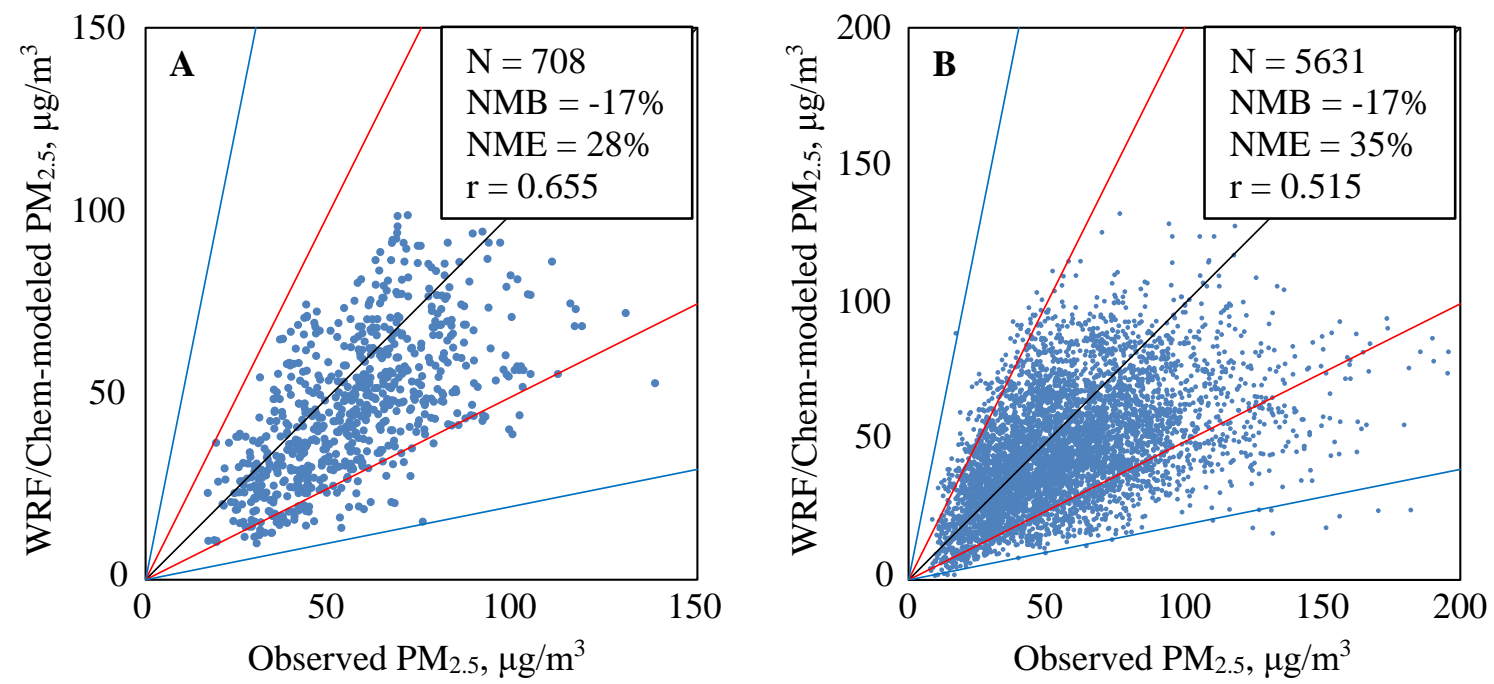

Figure S1. Validation between the WRF/Chem-modeled ambient $\mathrm{PM}_{2.5}$ concentrations and the observed values from CNEMC. ${ }^{6}$ Observations were collected at yearly (A) and monthly (B) scales, respectively, from 708 sites in 126 municipals in mainland China. The black lines were 1:1 lines, and the red and blue lines were double and 5-fold error lines, respectively. Sample sizes (N), normalized mean biases (NMBs), normalized mean errors (NMEs), and Spearman correlation coefficients ( $r$ ) were calculated for yearly and monthly scales, respectively. 

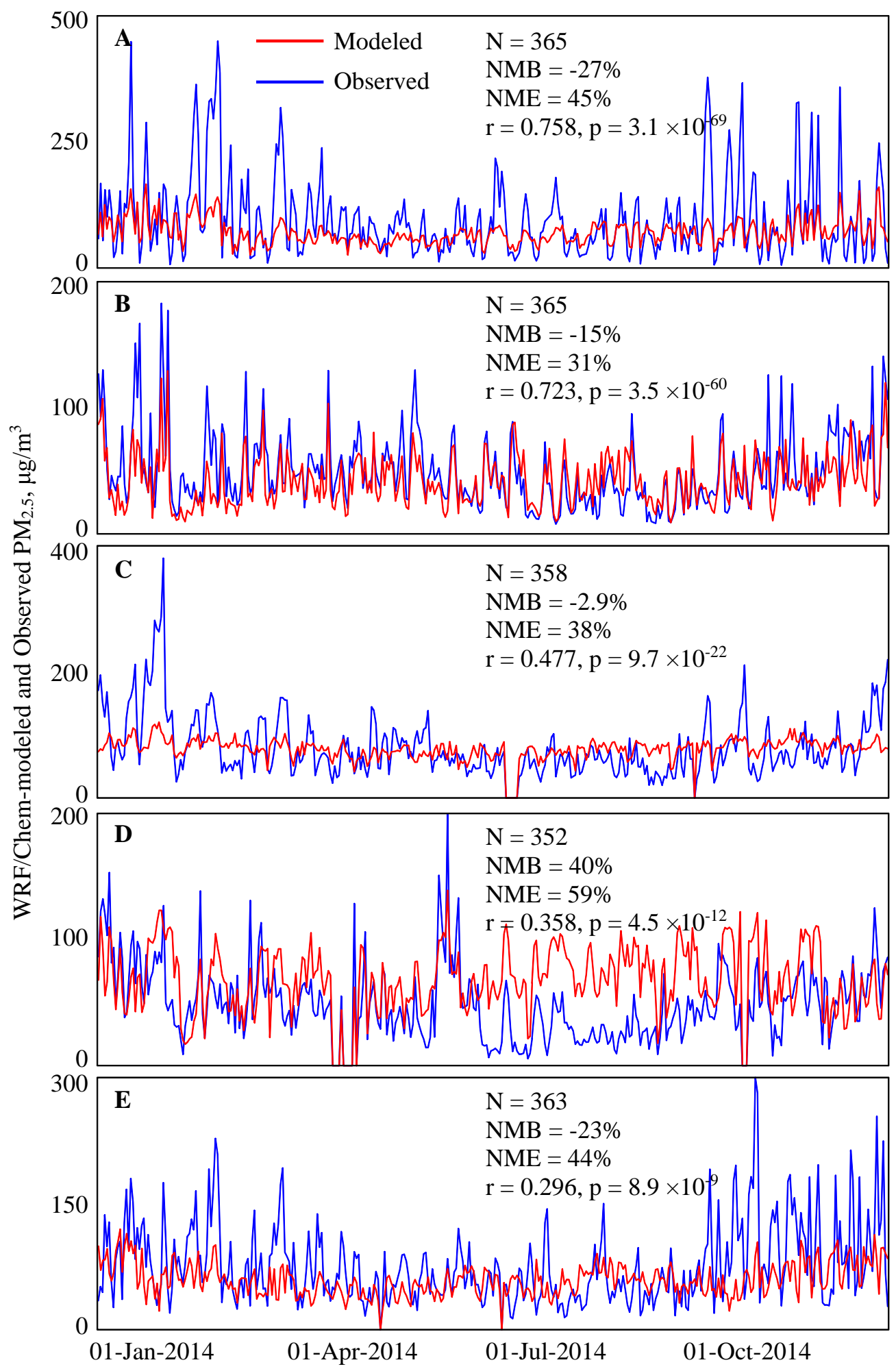

Figure S2. Validation between the WRF/Chem-modeled and observed daily ambient $\mathrm{PM}_{2.5}$ concentration time series. Monitored daily $\mathrm{PM}_{2.5}$ concentrations in Beijing (A), Shanghai (B), Chengdu (C), Guangzhou (D), and Shenyang (E) were collected from American embassy and consulates. ${ }^{7}$ Sample sizes (N), normalized mean biases (NMBs), normalized mean errors (NMEs), Spearman correlation coefficients (r) and $P$ values ( $\mathrm{p}$ ) were calculated, respectively. 

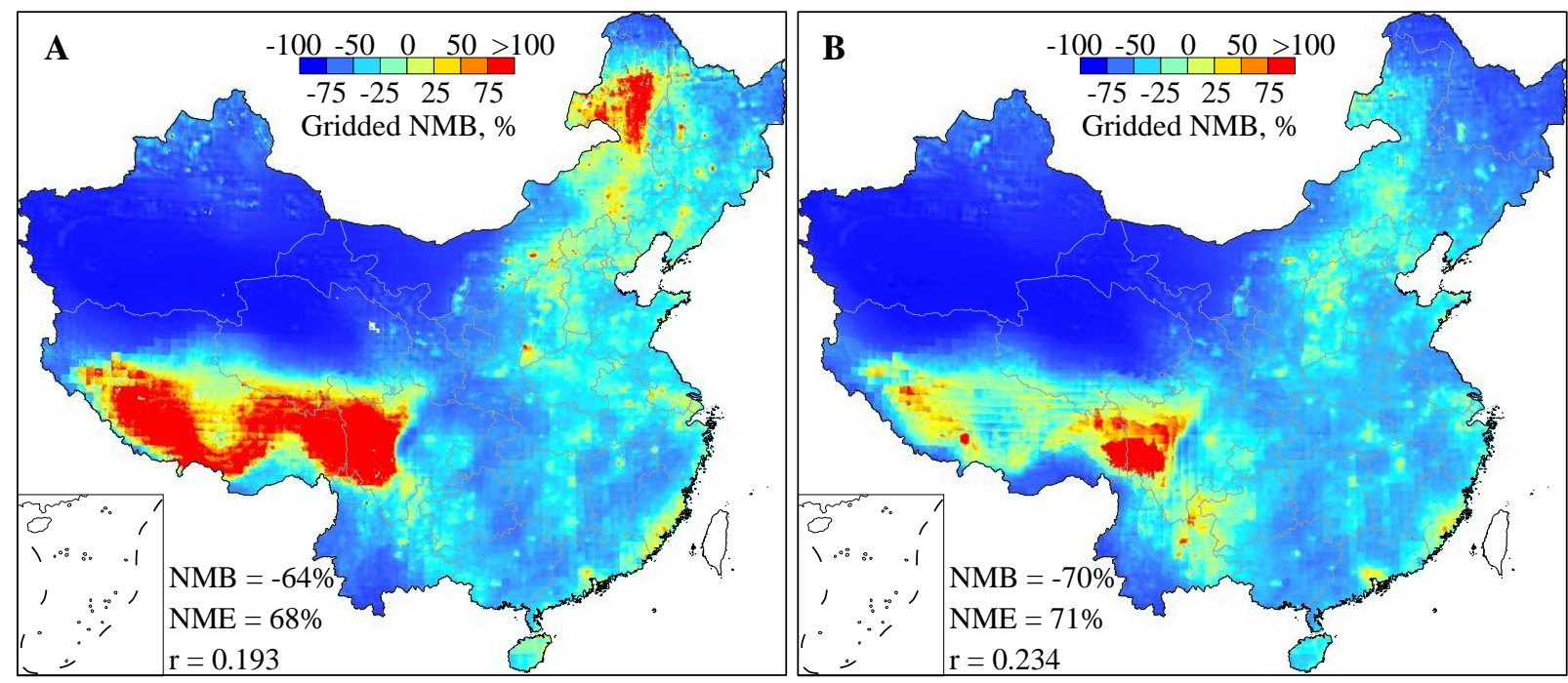

Figure S3. Spatial distributions of gridded normalized mean biases (NMBs) between the WRF/Chemmodeled gridded annual ambient $\mathrm{PM}_{2.5}$ concentrations and AOD/ATM-calculated gridded surface $\mathrm{PM}_{2.5}$ concentrations $^{8,9}$ in 2004 (A) and 2014 (B). Total normalized mean biases (NMBs), normalized mean errors (NMEs), and Spearman correlation coefficients (r) between the WRF/Chem-modeled and AOD/ATMcalculated annual $\mathrm{PM}_{2.5}$ concentrations at all grid cells in mainland China in 2004 and 2014 were calculated, respectively. 

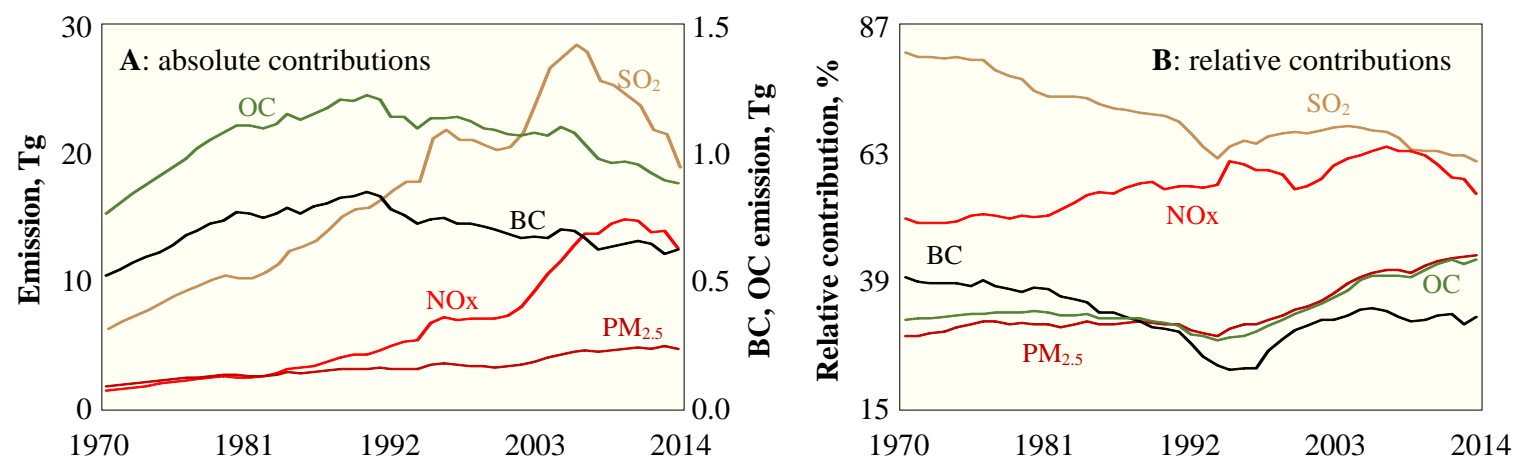

Figure S4. Temporal trends of emissions of major air pollutants generated from coal combustion for 1970 to 2014. The results are presented either as (A) absolute emissions or (B) relative contributions of coal to total anthropogenic emissions. 

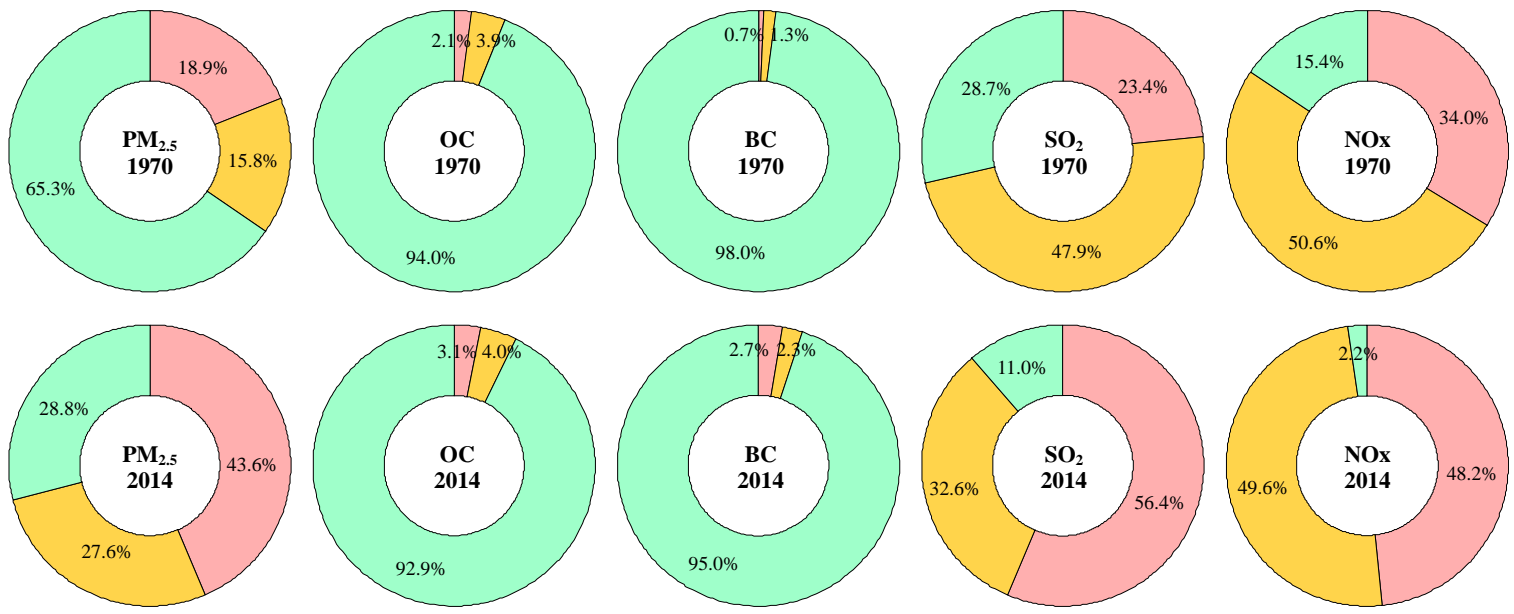

Power

Industry

Residential

Figure S5. Relative contributions of the power, industrial, and residential sectors to emissions of major air pollutants generated from coal combustion for 1970 and 2014. 


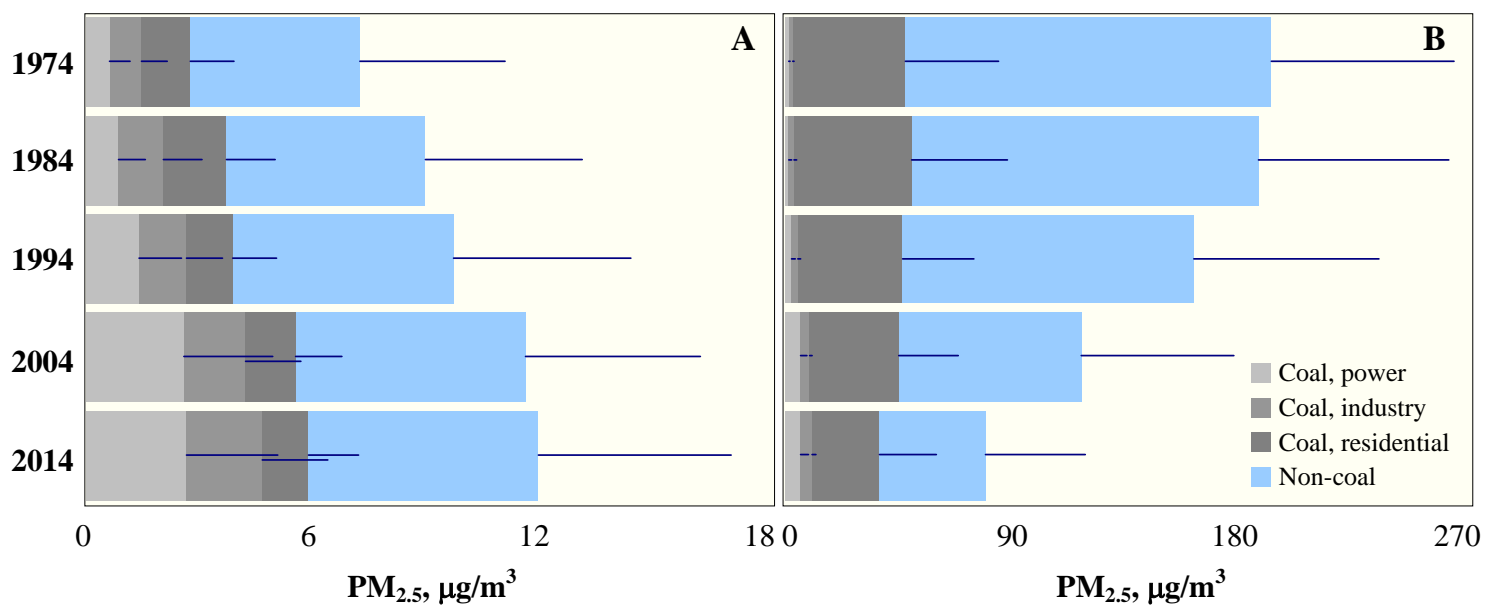

Figure S6. Outdoor (A) and indoor (B) $\mathrm{PM}_{2.5}$ concentrations originating from coal and noncoal anthropogenic sources. The contributions of coal sources are further divided into the power, industrial, and residential sectors. Means and standard deviations are presented. 

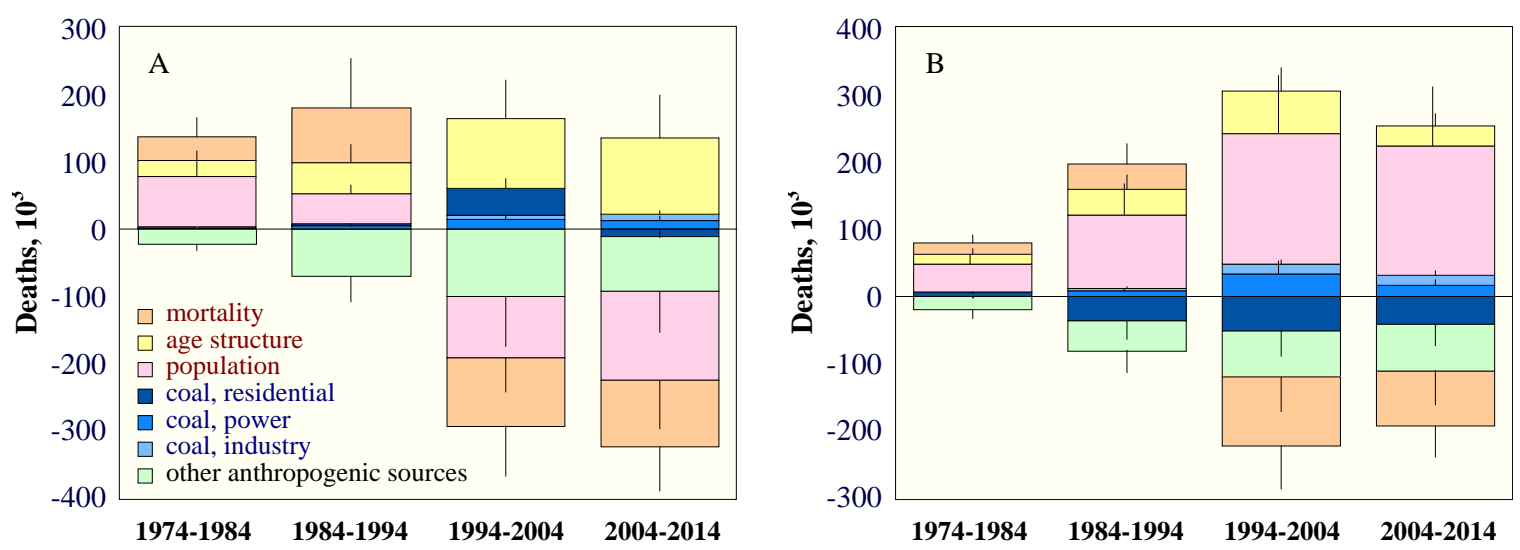

Figure S7. Cumulative contributions of major factors to changes in premature deaths for rural (A) and urban (B) population shown at 10-year intervals for 1974 to 2014. Driving forces include background mortality rates; age structures; population growth; and emissions from noncoal anthropogenic sources and coal used in the power, industrial, and residential sectors. The results are shown as medians at $95 \%$ uncertainty intervals, which are upper or lower bounds for positive and negative effects, respectively. 


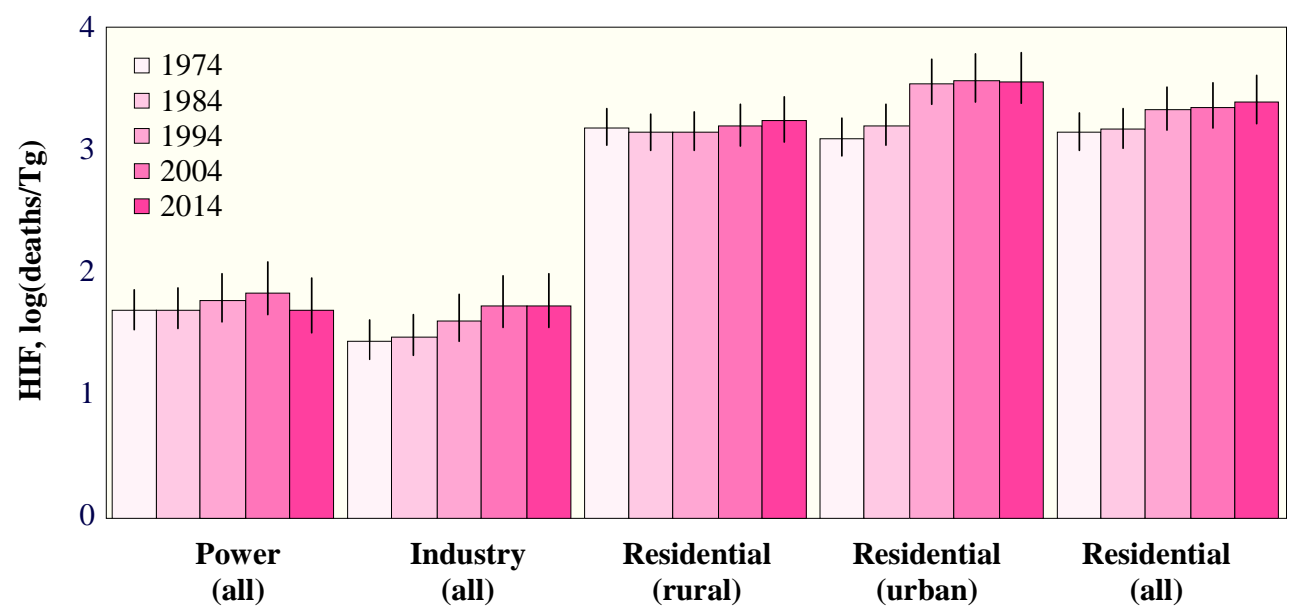

Figure S8. HIFs of coal used in the power, industrial, and residential sectors for 1974, 1984, 1994, 2004, and 2014. The results are shown as medians at $95 \%$ uncertainty intervals. Results for the residential sector are further separated for rural and urban population. 
Table S1. Validation between the WRF/Chem-modeled meteorological parameters (daily surface pressure, relative humidity, temperature, and mean wind speed) and the observed values from National Meteorological Information Center. ${ }^{10}$ Sample sizes (N), mean biases (MBs), mean normalized biases (MNBs), mean normalized errors (MNEs), normalized mean biases (NMBs), normalized mean errors (NMEs), and Spearman correlation coefficients (r) were calculated between the WRF/Chem-modeled and observed meteorological parameters in 1974, 1984, 1994, 2004, and 2014, respectively.

\begin{tabular}{|c|c|c|c|c|c|c|}
\hline Meteorological Parameter & Statistics & 1974 & 1984 & 1994 & 2004 & 2014 \\
\hline \multirow[t]{7}{*}{ Surface Pressure $(\mathrm{kPa})$} & $\mathrm{N}$ & 59494 & 60023 & 59495 & 60385 & 60585 \\
\hline & MB & -1.74 & -1.78 & -1.78 & -1.68 & -1.57 \\
\hline & MNB & $-2.0 \%$ & $-2.0 \%$ & $-2.0 \%$ & $-1.9 \%$ & $-1.8 \%$ \\
\hline & MNE & $2.2 \%$ & $2.2 \%$ & $2.3 \%$ & $2.1 \%$ & $2.1 \%$ \\
\hline & NMB & $-1.9 \%$ & $-1.9 \%$ & $-1.9 \%$ & $-1.8 \%$ & $-1.7 \%$ \\
\hline & NME & $2.1 \%$ & $2.1 \%$ & $2.2 \%$ & $2.0 \%$ & $1.9 \%$ \\
\hline & $\mathrm{r}$ & 0.964 & 0.962 & 0.951 & 0.964 & 0.967 \\
\hline \multirow[t]{7}{*}{ Relative Humidity (\%) } & $\mathrm{N}$ & 59859 & 60023 & 59494 & 60382 & 60581 \\
\hline & MB & 2.17 & 2.08 & 2.28 & 3.44 & -1.29 \\
\hline & MNB & $6.1 \%$ & $6.4 \%$ & $9.1 \%$ & $8.2 \%$ & $0.1 \%$ \\
\hline & MNE & $17 \%$ & $18 \%$ & $32 \%$ & $22 \%$ & $21 \%$ \\
\hline & NMB & $3.3 \%$ & $3.2 \%$ & $3.5 \%$ & $5.5 \%$ & $-2.1 \%$ \\
\hline & NME & $14 \%$ & $15 \%$ & $26 \%$ & $18 \%$ & $18 \%$ \\
\hline & $\mathrm{r}$ & 0.770 & 0.766 & 0.404 & 0.713 & 0.727 \\
\hline \multirow[t]{7}{*}{ Temperature (K) } & $\mathrm{N}$ & 59851 & 60024 & 59494 & 60381 & 60589 \\
\hline & MB & -0.58 & -0.68 & -1.48 & -1.38 & -1.04 \\
\hline & MNB & $-0.2 \%$ & $-0.2 \%$ & $-0.5 \%$ & $-0.5 \%$ & $-0.4 \%$ \\
\hline & MNE & $0.6 \%$ & $0.6 \%$ & $1.4 \%$ & $0.8 \%$ & $0.7 \%$ \\
\hline & NMB & $-0.2 \%$ & $-0.2 \%$ & $-0.5 \%$ & $-0.5 \%$ & $-0.4 \%$ \\
\hline & NME & $0.6 \%$ & $0.6 \%$ & $1.4 \%$ & $0.8 \%$ & $0.7 \%$ \\
\hline & $\mathrm{r}$ & 0.985 & 0.984 & 0.936 & 0.980 & 0.980 \\
\hline \multirow[t]{7}{*}{ Mean Wind Speed (m/s) } & $\mathrm{N}$ & 52263 & 54642 & 55574 & 59212 & 60576 \\
\hline & $\mathrm{MB}$ & -0.27 & 0.16 & 0.34 & 0.41 & 0.24 \\
\hline & MNB & $56 \%$ & $78 \%$ & $130 \%$ & $60 \%$ & $27 \%$ \\
\hline & $\mathrm{MNE}$ & $96 \%$ & $106 \%$ & $164 \%$ & $85 \%$ & $56 \%$ \\
\hline & NMB & $-9.8 \%$ & $6.4 \%$ & $14 \%$ & $18 \%$ & $11 \%$ \\
\hline & NME & $43 \%$ & $43 \%$ & $67 \%$ & $49 \%$ & $43 \%$ \\
\hline & $\mathrm{r}$ & 0.544 & 0.571 & 0.152 & 0.504 & 0.543 \\
\hline
\end{tabular}




\section{Supplementary References}

(1) Xiang, J. B.; Weschler, C. J.; Wang, Q. Q.; Zhang, L.; Mo, J. H.; Ma, R.; Zhang, J. F.; Zhang, Y. P. Reducing indoor levels of "outdoor PM2.5" in urban China: Impact on mortalities. Environ. Sci. Technol. 2019, 53 (6), 3119-3127.

(2) Shi, S. S.; Chen, C.; Zhao, B. Modifications of exposure to ambient particulate matter: Tackling bias in using ambient concentration as surrogate with particle infiltration factor and ambient exposure factor. Environ. Pollut. 2017, 220 (Part A), 337-347.

(3) Shi, S. S.; Chen, C.; Zhao, B. Air infiltration rate distributions of residences in Beijing. Build. Environ. 2015, 92, 528-537.

(4) Diapouli, E; Chaloulakou, A; Koutrakis, P. Estimating the concentration of indoor particles of outdoor origin: A review. J. Air Waste Manage. Assoc. 2013, 63 (10), 1113-1129.

(5) Ministry of Environmental Protection. Exposure Factors Handbook of Chinese Population (Adult Volume); China Environmental Science Press: Beijing, China, 2013.

(6) Historical Chinese Air Quality Observations; https://quotsoft.net/air (accessed Feb 9, 2021).

(7) U. S. Embassy and Consulates Air Quality Monitor; http://www.stateair.net/web/post/1/1.html (accessed Feb 9, 2021).

(8) Hammer, M. S.; van Donkelaar, A.; Li, C.; Lyapustin, A.; Sayer, A. M.; Hsu, N. C.; Levy, R. C.; Garay, M. J.; Kalashnikova, O. V.; Kahn, R. A.; Brauer, M.; Apte, J. S.; Henze, D. K.; Zhang, L.; Zhang, Q.; Ford, B.; Pierce, J. R.; Martin, R. V. Global estimates and long-term trends of fine particulate matter concentrations (1998-2018). Environ. Sci. Technol. 2020, 54 (13), 7879-7890.

(9) van Donkelaar, A.; Martin, R. V.; Li, C.; Burnett, R. T. Regional estimates of chemical composition of fine particulate matter using a combined geoscience-statistical method with information from satellites, models, and monitors. Environ. Sci. Technol. 2019, 53 (5), 2595-2611.

(10) National Meteorological Information Center. China Earth International Exchange Station Climate Data Daily Value Data Set (v3.0); http://data.cma.cn (accessed Feb 9, 2021). 